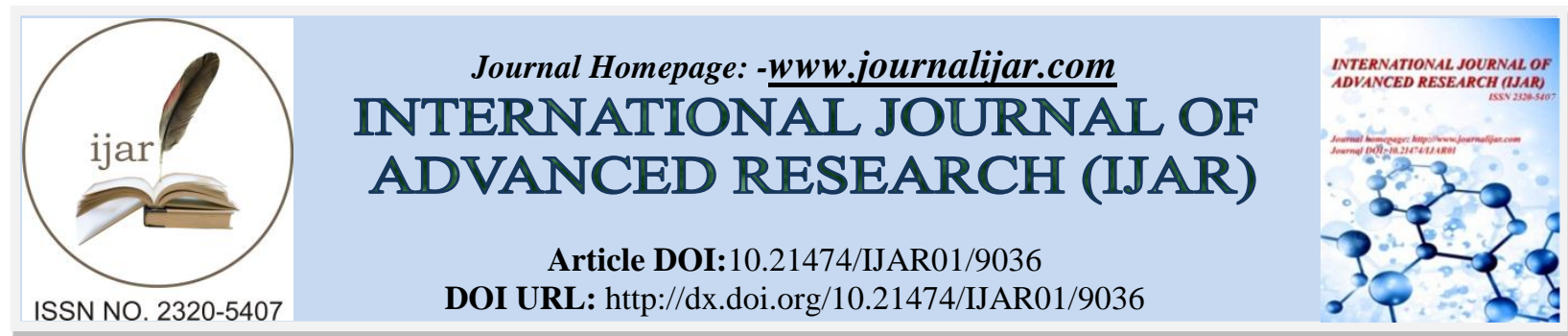

RESEARCH ARTICLE

\title{
SUBMUCOUS RESECTION AS THE SURGICAL ARMAMENTARIUM FOR THE DEVIATED NASAL SEPTUM -THOUGH SEEMS THEORETICAL BUT STILL IS MOST COMMONLY USED SURGERY.
}

Shahnaz Sheikh, Anushree bajaj and Vikrant vaze.

\section{Manuscript Info}

Manuscript History

Received: 10 March 2019

Final Accepted: 12 April 2019

Published: May 2019

\begin{abstract}
Background: Nasal obstruction is a symptom rather than a diagnosis. There is a wide range of medical and structural problems that could cause such a symptom. A deviated septum is a common structural condition of nose that involves a displacement of the nasal septum to one or both sides of nasal cavity causing unilateral or bilateral nasal obstruction respectively.About 80 percent of people have a deviated nasal septum which often develops as a result of an injury to the nose.Various surgical modalities like septoplasty,submucous resection are available for deviated nasal septum correction but because easy to perform and with satisfactory results submucous resection is still widely practiced.

Material and methods:The study was conducted at dr ulhas patil medical college jalgaon. A total of 230 patients were included in the study including both males and females. The age of patients included in the study ranges from 19 years to 65 years.All the operated patients were followed up at 6 months to 2 years postoperatively.Most of the patients about more than 76 percent achieved achieved short term relief of nasal obstruction and about 30 percent of people had persistent or recurrent nasal obstruction on long term follow up.

Results:The nasal obstruction was the most consistent symptom present in $100 \%$ of patients . Nasal obstruction was relieved in $76 \%$ of patients after SMR and in 73\% of cases after septoplasty.Patients having postoperative associated symptoms of snoring , headache, rhinorrhoea, sneezing ,hyposmia, epistaxis were improved of these symptoms after SMR to $60 \%, 62 \%, 31 \%, 30 \%, 30 \%$, and 13 respectively.The rates of short term and long term complivcations were relatively very low including septal haematoma $3 \%$, epistaxis $2 \%$, external nasal deformity $2 \%$ and septal perforation $3 \%$ of cases.

Conclusion: SMR, being relatively easy to perform and having similar complication and patient satisfaction rate as septoplasty, should be retained in surgical modilities for the deviated nasal septum.
\end{abstract}

Copy Right, IJAR, 2019,. All rights reserved.

\section{Introduction:-}

Nasal septum consists of three parts, columellar septum, membranous septum, and setum proper. Nasal septum forms the shape and provides support to the structure of nose.The constituents of the nasal setum are quadrateral

Corresponding author:-Anushree bajaj. 
cartilage,perpendicular plate of ethmoid, the vomer and minor contribution from from crest of nasal bones, nasal spine of frontal bone, rostrum of sphenoid, crest of palatine bones and the crest and anterior nasal spine of maxilla1. The submucous resection was first described by Freer in 1902 and by Killian in 1904. The preservation of bilateral muchoperichondrial flaps and cartilaginous support were considered essential in their technique2,3.The majior complications in this procedure are septal perforation, saddling of nose, and retraction of columella and residual deviation4.These led to emergence of septoplasty operation introduced by Cottle Aand Loring in19465.Septoplasty is correction of the deflected nasal septum with minimal removal of cartilage and/or bone. Material and methods:The study was conducted at Dr Ulhas pail medical college jalgaon fromJanuary 2017 to jan 2019 for correction of obstructive nasal septum.A total of 230 patienyts were included in the study. Total number of males included in the study were 172 and total number of females were 58. SMR was carried out on 130 patients and septoplasty on remaining 100 patients. The age of the patients included in the study were 19 to 60 years.Preoperative investigations including HB,CBC,KFT,BS,ECG,X-Ray chest, X-Ray PNS were done in all patients, NCCT NOSE and PNS in selected patients. Patientys having external nasal deformity along with DNS and Patienyts already operated for nasal surgeries were excluded from the study. All the patients were followed up to one year and all the findings including the complications and functional outcome were noted in OPD register. Most of the patients were operated under local anesthesia while few under general anesthesia.

\section{Results:-}

Nasal obstruction was present in all the patients preoperatively as shown in the table 1 . Nasal obstruction was relieved in $76 \%$ cases after SMR and $73 \%$ of cases after septoplasty. Statistical analysis showed the difference between the two procedures is insignificant $\mathrm{p}>0.05$. As shown below in table-2, Symptoms like headache, sneezing,rhinorrhoea,snoring $g$ and hyposmia were also relieved more frequently after SMR than septoplasty.

Table 1:-Frequency of preoperative symptoms in submucous resection vs septoplasty patients.

\begin{tabular}{|l|lc|lc|}
\hline Symptoms & $\begin{array}{c}\text { SMR } \\
\text { Number }\end{array}$ & $\begin{array}{c}\text { patients } \\
\text { Percentage }\end{array}$ & $\begin{array}{c}\text { Septoplasty } \\
\text { Number }\end{array}$ & $\begin{array}{c}\text { patients } \\
\text { Percentage }\end{array}$ \\
\hline Nasal obstruction & 130 & 100 & 100 & 100 \\
\hline Headache & 80 & 68 & 44 & 44 \\
\hline Rhinorrhoea & 60 & 51 & 42 & 42 \\
\hline Sneezing & 60 & 51 & 36 & 36 \\
\hline Snoring & 50 & 43 & 34 & 22 \\
\hline Nasal speech & 50 & 43 & 22 & 22 \\
\hline Dry/sore throat & 45 & 39 & 22 & 16 \\
\hline Hyposmia & 35 & 30 & 16 & 12 \\
\hline Epistaxis & 15 & 13 & 12 & \\
\hline
\end{tabular}

Table 2:-Functional results of SMR vs Septoplasty

\begin{tabular}{|l|lc|lc|}
\hline Symptoms & $\begin{array}{l}\text { SMR } \\
\text { Number }\end{array}$ & $\begin{array}{c}\text { patients } \\
\text { Percentage }\end{array}$ & $\begin{array}{l}\text { Septoplasty } \\
\text { Number }\end{array}$ & $\begin{array}{c}\text { patients } \\
\text { percentage }\end{array}$ \\
\hline Nasal obstruction & $100 / 130$ & 76 & $73 / 100$ & 73 \\
\hline Headache & $50 / 80$ & 62 & $24 / 44$ & 54 \\
\hline Rhinorrhoea & $19 / 60$ & 31 & $14 / 42$ & 33 \\
\hline Sneezing & $18 / 60$ & 30 & $11 / 36$ & 50 \\
\hline Snoring & $30 / 50$ & 60 & $17 / 34$ & 59 \\
\hline Nasal speech & $32 / 50$ & 62 & $13 / 22$ & 40 \\
\hline Dry/sore throat & $25 / 45$ & 55 & $9 / 22$ & 43 \\
\hline Hyposmia & $26 / 35$ & 74 & $7 / 16$ & 50 \\
\hline Epistaxis & $8 / 15$ & 53 & $6 / 12$ & \\
\hline
\end{tabular}

Table 3:-Postoperative complications of submucous resectionj vs septoplasty

\begin{tabular}{|l|lc|lr|}
\hline Complications & $\begin{array}{l}\text { SMR } \\
\text { Number }\end{array}$ & $\begin{array}{c}\text { patients } \\
\text { Percentage }\end{array}$ & $\begin{array}{l}\text { Septoplasty } \\
\text { Number }\end{array}$ & $\begin{array}{c}\text { patients } \\
\text { percentage }\end{array}$ \\
\hline Crust formation & $11 / 130$ & 8 & $6 / 100$ & 6 \\
\hline Altered dental sensation & $8 / 130$ & 6 & $5 / 100$ & 5 \\
\hline
\end{tabular}




\begin{tabular}{|l|ll|ll|}
\hline Septal perforation & $4 / 130$ & 3 & $2 / 100$ & 2 \\
\hline Septal haematoma & $4 / 130$ & 3 & $2 / 100$ & 2 \\
\hline Saddling & $3 / 130$ & 2 & $1 / 100$ & 1 \\
\hline Bleeding & $3 / 130$ & 2 & $4 / 100$ & 4 \\
\hline Adhesions & $3 / 130$ & 2 & $1 / 100$ & 1 \\
\hline Columellar retraction & $4 / 130$ & 3 & $2 / 100$ & 2 \\
\hline Residual deviation/deformity & $4 / 130$ & 3 & $2 / 100$ & 2 \\
\hline total & $40 / 130$ & 27 & $26 / 100$ &
\end{tabular}

Sadle nose deformity occurred in 3(2\%) cases after SMR and in 1(1\%) cases after septoplasty.Columellar retraction with loss of tip projection was found in 4(2\%) of cases after SMR and 3(2\%) of cases after septoplasty.Residual deviation was found in 4(3\%) of cases after SMR and 2(2\%) of cases after septoplasty. Crust formation was present in $8 \%$ cases after SMR and 6\% cases after septoplasty. Altered dental sensation were complained by $6 \%$ subjects after SMR and 5\% after septoplasty. In 3\% and 2\% of cases septal haematoma were discovered after SMR and septoplasty respectively.Septal haematoma resolved in all the cases with drainage and altered dental sensations were temporary but took eight weeks to recover. 4 cases after SMR and and 2 cases after septoplasty were found to have septal perforation. 3 patients had epistaxis after SMR and 4 patients after septoplasty .cases

\section{Discussion:-}

Functional results were better in group in which SMR(74\%) was done than in septoplasty(72\%) . we used nasal obstruction as main clinical parameter to get relieved in postoperative period since it was present in all patients in both groups .however international studies show better result in septoplasty $(66 \%)$ than SMR $(60 \%){ }^{6}{ }^{6}$ Fjermedal7 also quoted studies which show that results in septoplasty surgery were not better in 25-35\% cases . Jessen 8et all found that although the long term objective nasal patency improved after septoplasty but the long term sensation of obstruction was not improved ,he suggested that unfavourable airflow pattern due to postoperative anatomical changes may be the reasin for the same.$^{8}$ according to the research by Barr9 , the altered airflow pattern because of abnormal mucociliary function caused the sensation of remnant nasal obstruction in the postopertative period .

In out study the complication of septal perforation occurred in $4(3 \%)$ cases after SMR and $2(2 \%)$ cases in septoplasty .in the study by Zia and Butt septal perforation was found in $2 \%$ cases.$^{10}$ and in $1.6 \%$ cases in septoplasty and $8 \%$ cases after SMR according to study by Haraldsson 11. septal perforations are most commonly quoted due to tearing of the opposing mucosal flap, in such cases one side should be closed ${ }^{12,13 .}$ perforations are found to be more in cases of revision surgery due to disturbed planes and resultant fibrosis .

Adhesions were seen in 3 (2\% cases after SMR while in $1 \%(1)$ case after septoplasty in all the patients adhesions were released under local anesthesia during the following visits .causes of afhesions coul;d be blood clots, infection surgery both on the lateral wall and the septum and postoperative slough and crust formation .In other study there was adhesions seen in 7\% and $8 \%$ cases of SMR and septoplasty respectively ${ }^{6,10}$ adhesions can be be best avoided by control of infection, minimal trauma at the time of surgery, placement of intranasal splints, use of liquid paraffin and nasal decongestant drops postoperatively. In the sudy by Shone and Clegg $11 \%$ cases developed adhesions because of synchronous surgery on lateral wall and septum ,trauma during the surgery due to nasal speculum and nasal packs..$^{17,14}$

Altered dental sensations in the upper incisors were seen in $8(6 \%)$ cases after SMR while in 5(5\%) cases after septoplasty . in another study higher rates of altered dental sensation were seen in $31 \%$ cases of SMR while in $11 \%$ cases of septoplasty.$^{17,14}$ crusting was found in $8.3 \%$ cases of SMR while in $7 \%$ cases of septoplasty and was found to be lesser in other studies.$^{11,12}$ the reasons for the same can be quoted to be septal perforation and surgery on the lateral wall (turbinectomy ), . postoperative haematoma was low in our cases (1.8\%)than in study by Fjermedel et all with $6.9 \%{ }^{?}$

Cosmetic results of septoplasty were better than in SMR . nasal bridge depression was found in 1\% after septoplasty while $2.5 \%$ cases after SMR in our study, while 4(3\%) cases of SMR and 2(2\% )cases of septoplasty developed columellar retraction .Philips noted same in $21 \%$ cases of SMR15 while Samad found the same in $8.5 \%$ cases of septoplasty.$^{16}$ our results are probably better because of shorter period of postoperative evaluation, or because the preoperative shape of the nose was not documented with exact precision in our study .saddle nose deformity is attributed to gradual absorption of triangular cartilaginous fragment around the rhinion along the dorsum of the nose 
, especially when the fragment is anadvertently detached during the surgery.${ }^{17}$ however the collumelar retraction occurs from tissue defiency of the leading edge of septum and often the anterior nasal spine from the midline ${ }^{6}$

in our study residual deformity was4(3\% )in compared to other studies by Muhammad IA of $6 \% .{ }^{6}$ the inadequate mobilization of the flaps that relieves the tension an resilience of the septum may be responsible for recurrent displacement and deformity ${ }^{19}$ recurrence of deflection or deformity after SMR may be due to angulation or deformity of the neochongrogenesis in the septal area after SMR ${ }^{20}$

our study does not reveal any significant difference in functional outcome and complication rates of both the procedures i.e submucous resection and septoplasty for symptomatic deviated nasal septum .

\section{Conclusion:-}

There has been increasing step of otolaryngologists towards septoplasty than SMR since it is conservative and cartilage is preserved and because of the lower rate of complications . but when done with utmost care and in experienced hands SMR yields results equally well as in our study . in reality majority of otolaryngologists employ a functional combination of both SMR and septoplasty with excellent results . our study does not reveal any significant difference in functional outcome and complication rates of both the procedures i.e submucous resection and septoplasty for symptomatic deviated nasal septum.

\section{References:-}

1. Dhingra PL. Diseases of ear, nose and throat. 4th Ed: 2007;26:140

2. Freer OT. The correction of deflections of the nasal septum with minimum of traumatization. JAMA 1902;4:619.

3. Killian G. Die submucose Fensterresektion der Nasenscheidewand. Arch Laryngol Rhinol 1904;16:362-87.

4. Tzadik A, Gilbert SE, Sade J. Complications ofsubmucous resection of the nasal septum. Arch Otolaryngol 1988;245:74-6.

Blaugrund SM. The nasal septum and choncha bullosa. Otolaryngol. Clin North Am 1989;22:291. Muhammad IA, Nabil-ur-Rahman. Complications of the surgery for deviated nasal septum. J Coll Physcians Surg Pak 2003;13:565-8. Fjermedal O, Saunte C, Pedersen S. Septoplasty and/or submucous resection? 5 years nasal septum operations. J Laryngol Otol 102:796-8. Jessen M, Ivarsson A, Malm L. Nasal airway resistance and symptoms after functional septoplasty: comparison at 9 months and 9 years. Clin Otolaryngol 1989;14:231-4. Barr GS. The effect of submucous resection of the nasal septum on mucociliary transport and nasal airway. Clin Otolaryngol $\quad 1989 ; \quad 14: \quad 127-30$. Zia MR, Butt MIH. Overview of septoplasty vis-àvis S.M.R. Specialist 1996;12:235-8. Gomal Journal of Medical Sciences January-June 2011, Vol. 9, No. 126

5. Haraldsson PO, Nordemar H, Anggard A. Long term results after septal surgery - submucous resection versus septoplasty. ORL 1987;49:21822.

6. Murthy P, Mckerrow WS. Nasal septal surgery: Is routine follow-up necessary? J Laryngol Otol 1995;109:3203.

7. Sirnivasan V, Arasaratnam RB, Jankelowitz GA.Day-case septal surgery under general anaesthesia and local anaesthesia with sedation. J Laryngol Otol 1995;109:614-7.

8. Phillips JJ. The cosmetic effects of submucous resection. Clin Otolaryngol 1991;16:179.

9. Samad I, Steven HE, Maloney A. The efficacy ofnasal septal surgery. J Otolaryngol 1992;21:88.

10. Min YG, Chung JW. Cartilaginous incision inseptoplasty. ORL J Otorhinolaryngol Relat Spec 1996; 58:51-4.

11. Shone GR, Clegg RT, Nasal adhesions. JLaryngol Otol 1987;101:555-7.

12. Iqbal M, Mohibullah, Saeedullah, Khan H, Shah JI. Septoplasty versus submucous resection in young adults. JPMI 1999;13:109-12.

13. Low WK, Willat DJ. Submucous resection fordeviated nasal septum: a critical appraisal. Singapore Med J 1992;33:617-9.

14. Aguodo DL, Monserrat JR, Pinero BP, Banales MEC, Gutierres R, Flores LD. Neochondro-genesis in the septal area after submucous cartilage resection. Acta Otolaryngol 1992;112: 539. 